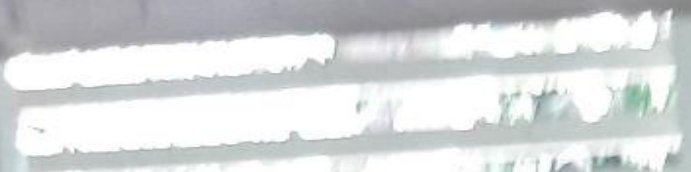

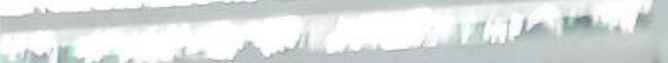
$y^{2}=4$

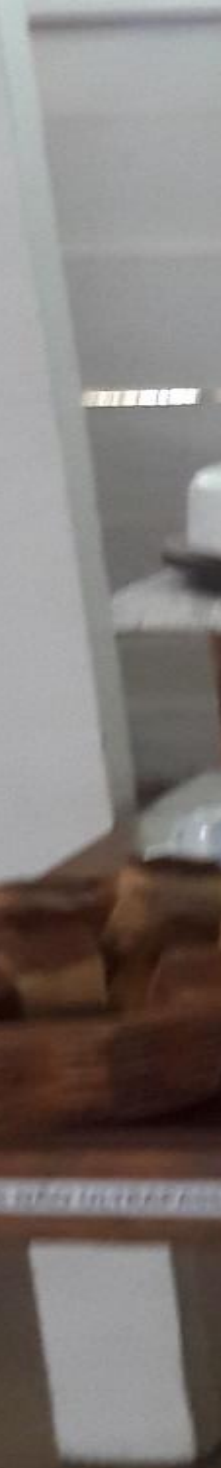

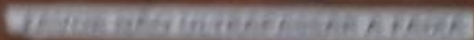

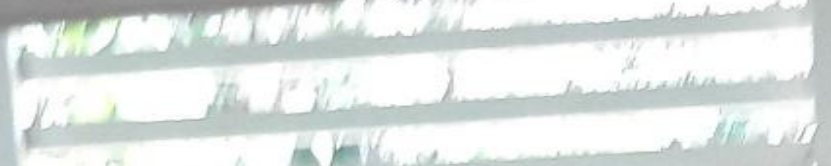

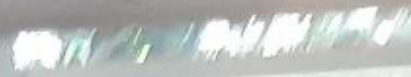

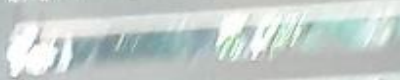

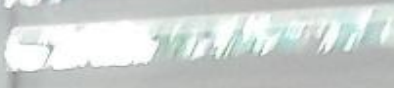
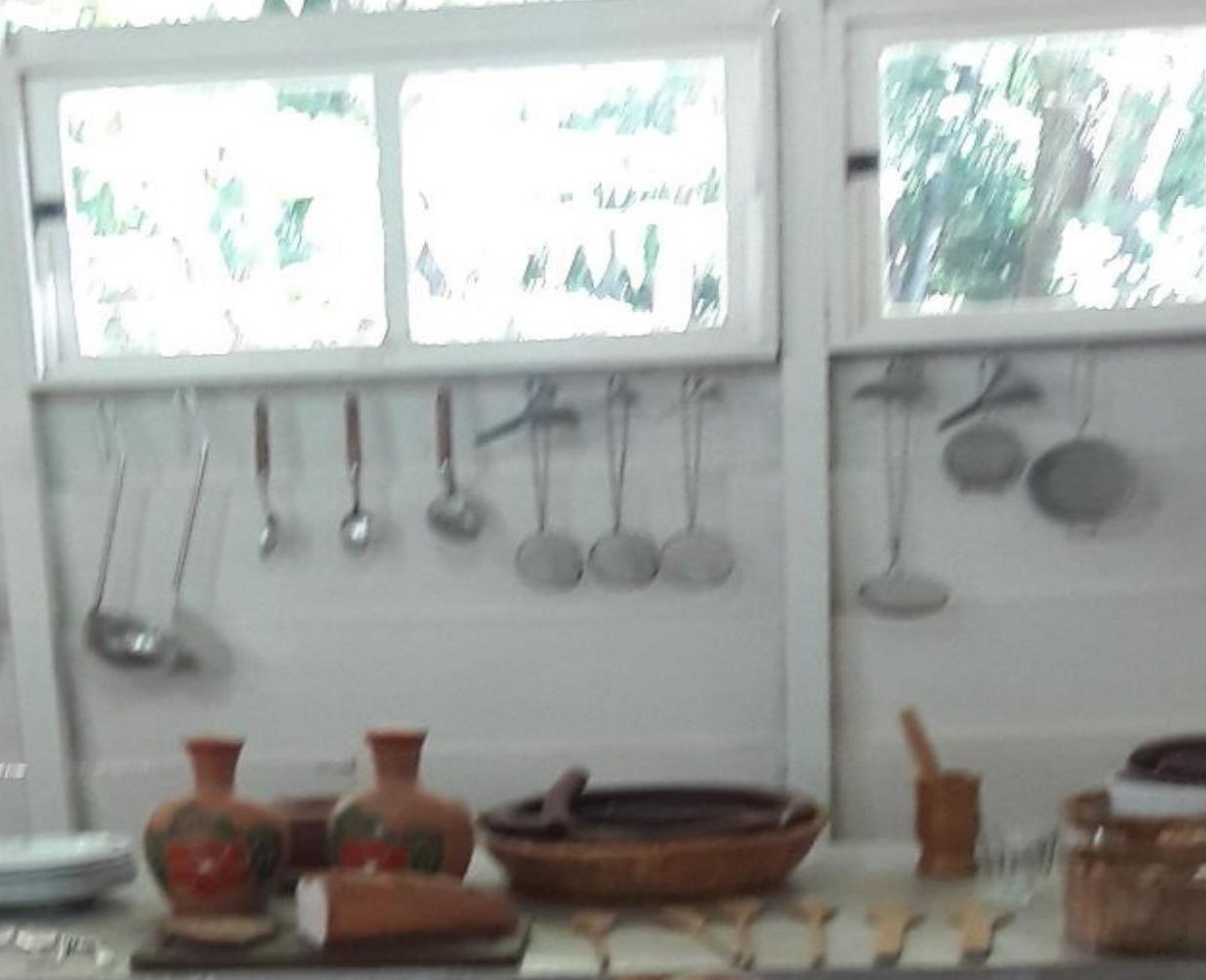

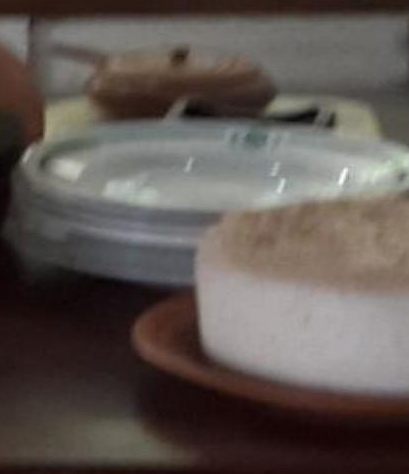




\section{Turismo Rural e Comunitário como vetores para o fortalecimento de cadeias agroalimentares familiares e agroecológicas}

Rural and Community Tourism as vectors for strengthening family and agroecological agrifood chains.

Julia Coelho de Souza ${ }^{1}$

\footnotetext{
${ }^{1}$ Bacharel em Turismo e Mestre em Desenvolvimento Rural pela UFRGS, gestora de projetos sociais e economia solidária. juliacoel@gmail.com
} 


\section{RESUMO}

Verifica-se cada vez mais o interesse na relação estabelecida entre Turismo Rural e Comunitário com as cadeias agroalimentares familiares e agroecológicas. Esse artigo tem como objetivo aproximar conceitos e práticas em Turismo Rural e Comunitário com economia solidária. A partir da perspectiva da sociologia econômica foram estudados grupos de agricultores ecologistas organizados para a produção e comercialização enquanto atores sociais portadores de distintas lógicas para a realização de suas práticas e reprodução social. Apresento então provocações para reflexões e debates que subsidiem o aprofundamento dessas inflexões. Que relações sociopolíticas se estabelecem com o turismo através da perspectiva do consumo? Que contribuições o Turismo Rural e Comunitário pode dar para a sustentação de cadeias agroalimentares baseadas na agricultura familiar e na agroecologia, e ainda, para o fortalecimento das comunidades rurais? A partir do momento então que o turismo convencional com características mais consumistas e colonizadoras se depara com uma comunidade articulada para utilizar o turismo como ferramenta para fixação em seu território e reprodução de seus modos de vida (em outras palavras, como ferramenta de resistência), conflitos de diversas ordens podem surgir.

Palavras-chave: Turismo Rural e Comunitário, cadeias agroalimentares familiares, economia solidária, sociologia econômica

\section{Abstract}

There is an increasing interest in the relationship between rural and community tourism with family and agroecological agri-food chains. This article aims to approach concepts and practices in Rural and Community Tourism with solidarity economy. . From the perspective of economic sociology, groups of ecological farmers organized for production and commercialization were studied as social actors with different logics to carry out their practices and social reproduction. I then present provocations for reflections and debates that subsidize the deepening of these inflections. What socio-political relations are established with tourism through the consumption perspective? What contributions can rural and community tourism provide for the support of agro-food chains based on family agriculture and agroecology, and also for the strengthening of rural communities? From that moment on, conventional tourism with more consumerist and colonizing characteristics is confronted with an articulated community to use tourism as a tool to fix its territory and reproduce its ways of life (in other words, as a resistance tool). Conflicts of various orders may arise.

Keywords: Rural and Community Tourism, family agrifood chains, solidarity economy, economic sociology

\section{INTRODUÇÃO}

Este artigo busca aproximar os conceitos e práticas em Turismo Rural e de Turismo de Base Comunitária com os debates a respeito da produção, comercialização e consumo de alimentos com base na agricultura familiar, na agroecologia e nas práticas de economia solidária muitas vezes envolvidas nesses processos.

Trata-se, em certa medida, de buscar sequências à minha dissertação de mestrado intitulada "Comércio solidário na prática do Núcleo Litoral Solidário da Rede Ecovida de Agroecologia", defendida em 2008, no Programa de Pós Graduação em Desenvolvimento Rural (PGDR/UFRGS), agregando agora minha área de graduação, o Turismo com ênfase no Planejamento Público, e minhas práticas profissionais em gestão de projetos e organização de grupos rurais para a comercialização em 
espaços alternativos e geração de renda através do fomento ao turismo de base comunitáriaª ${ }^{2}$ A partir da perspectiva da sociologia econômica, trabalhei no mestrado com grupos de agricultores ecologistas organizados para a produção e comercialização enquanto atores sociais portadores de distintas lógicas para a realização de suas práticas e reprodução social.

Agora, busco novas questões e problemáticas. Neste ensaio, trato do fortalecimento de organizações de agricultura familiar e de base ecológica através de cadeias curtas de comercialização pela perspectiva da multifuncionalidade e da pluriatividade, tendo o turismo como vetor. Apresento então provocações para reflexões e debates que subsidiem o aprofundamento dessas inflexões.

Que relações sociopolíticas se estabelecem com o turismo através da perspectiva do consumo? Que contribuições o Turismo Rural e Comunitário pode dar para a sustentação de cadeias agroalimentares baseadas na agricultura familiar e na agroecologia, e ainda, para o fortalecimento das comunidades rurais?

Ainda que viajar ou fazer turismo seja uma ação composta de elementos entramados em complexas relações, objetivas e subjetivas, o artigo busca trazer a ênfase aos aspectos relacionados com a produção e reprodução de cadeias agroalimentares vinculadas e geradas pela agricultura familiar e pela agroecologia.

Assumo duas posições iniciais: que o turismo contém em si uma ideia hegemônica, mais a ver com necessidades de mercado do que com demandas sociais. Segundo, que a existência de uma demanda contemporânea pelo consumo de alimentos mais saudáveis, estende-se também para produtos e serviços fora dos padrões convencionais, o que configura um cenário favorável à busca por viagens mais orientadas a preservação ambiental, com respeito e consideração às comunidades locais envolvidas e seus processos. Pela perspectiva da acolhida, a disposição de famílias a receberem visitantes em suas casas e em seus lugares, podem criar nas comunidades tanto uma atmosfera quanto fluxos de relações e iniciativas que fazem com que os locais qualifiquem-se como espaços plurais, criativos e atrativos também aos moradores desse local. Ou seja, a modificação de um 'simples' paradigma no que diz respeito ao viajar e receber, e a forma de gestão desse sistema, gera uma série de benefícios em rede para o território envolvido.

A partir do momento então que o turismo convencional com características mais consumistas e colonizadoras se depara com uma comunidade articulada para utilizar o turismo como ferramenta para fixação em seu território e reprodução de seus modos de vida (em outras palavras, como ferramenta de resistência), conflitos de diversas ordens podem surgir.

2 Em especial, me refiro às experiências junto ao NEA/ ITCP/ UFRGS (Núcleo de Economia Alternativa, Incubadora Tecnológica de Cooperativas Populares da Universidade Federal do Rio Grande do Sul) na organização e gestão do Espaço Contraponto - Entreposto de cultura, saúde e saber, e na equipe executora das Medidas Compensatórias à Comunidade Quilombola de Morro Alto, RS, afirmadas no termo de compromisso IBAMA/ DNIT (Instituto Brasileiro do Meio Ambiente e dos Recursos Naturais Renováveis / Departamento Nacional de Infraestrutura e Transportes). 


\section{DESENVOLVIMENTO: ASPECTOS COMUNS ÀS CADEIAS AGROALIMENTARES E AO TURISMO CONVENCIONAL}

Existe uma diversidade de referências e quadros teóricos tem se dedicado a identificar, classificar e analisar os fenômenos que envolvem a agricultura e a alimentação moderna. Friedmann e McMichael (1989) identificam os Regimes Alimentares historicamente construídos, caracterizando as formas de produção agrícola e consumo alimentar. Nessa análise, o Primeiro Regime Alimentar, datado de 1870 e 1930, se contextualiza nas importações de trigo e carne pela Europa a partir dos estados coloniais que, em contrapartida, serviam como mercado consumidor para os produtos industrializados ingleses, exportando em especial trabalho, capital e bens manufaturados; o Segundo Regime Alimentar, no período pós-guerra, se inicia com a ajuda alimentar promovida pelos EUA através da exportação dos excedentes de cereais para a Europa, o que incentivou fortemente a industrialização do Terceiro Mundo, na mesma medida em que intensificou o vínculo de dependência alimentar entre os seus mercados; e o Terceiro Regime Alimentar, atual, se caracteriza pelo oligopólio das corporações agroalimentares, pela globalização das cadeias de proteína animal, pela crescente vinculação entre os mercados de petróleo e alimentos e pela expansão das redes de atacados como espaço de comércio.

O modelo de desenvolvimento rural baseado em commodities, inversões internacionais e em exportações, se origina então nos arranjos sociais e políticos que vem sendo configurados desde a segunda metade do século passado, com a implementação a nível mundial de um modelo de desenvolvimento cujas principais estratégias foram modernização da agricultura, a industrialização e a urbanização (CONTERATO \& FILLIPI, 2009; PACÍFICO, 2009; OTTMANN, 2012; PREISS, 2015; PREISS e MARQUES, 2005). De acordo com a Comissão Econômica para a América Latina e o Caribe - CEPAL, a industrialização da agricultura e o sistema de intensificação da produção foram incentivados como caminho para a superação do subdesenvolvimento, tendo o rural a função primordial de produzir alimentos em grandes quantidades a custos baixos para abastecer os centros urbanos (PACÍFICO, 2009). A industrialização da agricultura provocou mudanças profundas tanto nas formas de produção quanto nos padrões de consumo e na dieta da população mundial (GOODMAN \& REDCLIFFE, 1991).

Ao mesmo tempo, esse modelo gerou um cenário de significativa degradação ambiental e escasseamento de recursos naturais não renováveis, além de outros fatores sociais amplamente documentados na literatura, como desagregação social, aumento do desemprego e da desigualdade social, o endividamento dos agricultores, a desvalorização cultural das populações do campo e uma intensa migração para a cidade (LEFF, 2001; RAYNOUT, 2006; OTTMANN, 2012; PREISS, 2015). Em especial nos países da América Latina, a modernização da agricultura inviabilizou técnica e economicamente muitas propriedades rurais de pequeno porte e de organização produtiva familiar 
(FERRER, 2014).

Diversos estudos apontam para o esgotamento desse padrão, em especial, pela ênfase no meio-ambiente, na agro e biodiversidade e nos agricultores que não aderiram à modernização da agricultura. Pela perspectiva técnico-produtiva, evidenciam-se os limites de produtividade em função da rápida degradação dos recursos naturais; economicamente, as baixas de preços e as restrições de mercado se impõe aos produtores rurais, gerando problemas sociopolíticos como a perda de autonomia dos produtores e o êxodo rural (DAL SOGLIO et all, 2007). Ploeg (2009) compreende que a combinação de três fatores geraram a crise agrária: a industrialização da agricultura, a introdução do mercado global como princípio ordenador da produção e comercialização agrícola via grandes empresas atacadistas (PREISS, 2015). Tais empresas constituem o que o autor denomina como "Impérios Alimentares", visto que exercem um poder monopólico crescente sobre a produção, o processamento, a distribuição e o consumo de alimentos. As exigências de alta produtividade limitam o tipo de produtores rurais que podem se inserir competitivamente, a depender de seu tamanho e das condições para a adesão aos pacotes tecnológicos (seja em relação à mecanização, seja em relação aos plantios, envolvendo a compra sistemática de sementes). Àqueles pequenos e médios que aderiram aos pacotes, constata-se que os aumentos de produtividade estimularam a queda generalizada nos preços dos produtos agropecuários, que somados aos altos custos de produção, acabam tencionando o retorno financeiro para os agricultores e criam um estrangulando nas condições de reprodução social (PLOEG, 2009). A existência de uma série de intermediários envolvidos na cadeia de abastecimento, faz com que os valores antes recebidos de forma integral pelo produtor, passem a ser distribuídos entre diferentes atores que atuam no processo.

Na mesma via, o turismo em sua concepção hegemônica representa uma das facetas mais utilitaristas da globalização liberal. De acordo com Buades, uma das maiores particularidades do turismo "es que se internacionaliza para proporcionar servicios en cualquier lugar del mundo a los mismos consumidores que tiene en su territorio de origen en lugar de buscar crear un consumo local de sus productos". Nessa lógica, se criam produtos e serviços relacionados a si mesmos "creando una plataforma de negocio ideal para generar clústers de alto rendimiento económico." (2014, 57). Amplamente compreendida como indutora de desenvolvimento, a atividade turística é tratada a partir de medições de desempenho e por critérios econômicos, considerando os ingressos gerados nos destinos e os investimentos realizados principalmente pelos setores imobiliário, de transportes, de comunicações e de entretenimento ${ }^{3}$. São os parâmetros utilizados por investidores do turismo, sejam empreendimentos de grande porte, sejam ações de governos com resultados a curto prazo. Neste cenário, é imprescindível considerar a amplitude dos impactos negativos que podem ser

3 Como pode ser visto na página web da OIT - Organização Internacional do Turismo, www.unwto.org. 
ocasionados, como gentrificação ${ }^{4}$, degradação ambiental, cultural, social, da paisagem e consequente descaracterização do território e das atividades turísticas (BRASIL, 2008); também, precarização do trabalho, prostituição, perda de identidades coletivas e pobreza, são aspectos negativos amplamente documentados na literatura e na imprensa. Tais impactos podem ser ocasionados por descaso de investidores e pela falta de planejamento nas localidades receptoras.

Conceitualmente, o Turismo se define por "uma combinação complexa de interrelacionamentos entre produção e serviços, cuja composição integra-se uma prática social com base cultural, com herança histórica, a um meio ambiente diverso, relações sociais de hospitalidade, troca de informações interculturais" (MOESCH, 2002:09). O produto turístico é o somatório desta dinâmica sociocultural. Em que pese o termo 'produto', os atrativos e o modo de vida constituem-se de subjetividades e são permeados por recursos estéticos: costumes, patrimônios materiais e imateriais, paisagens, contato com a natureza e com práticas tradicionais diversas, desde a agricultura à festas e manifestações culturais. O consumo desse produto se relaciona com a fruição, a interação e a vivência. Por isso, tratar o turismo como uma indústria, termo amplamente difundido e muitas vezes acriticamente reproduzido, é mais bem uma perspectiva utilitarista, resultante e resultado do turismo de massas e do turismo de alta classe - as formas mais impactantes de turismo em termos sociais e ambientais. Aqui trabalho com a noção de turismo como uma atividade, em detrimento da noção de indústria, que se faz a partir da relação entre uma complexidade de fatores, ações, atores sociais, produtos, bens, serviços, patrimônios, políticas, configurando um sistema (BENI, 1998; NOSCHANG, 2014).

Tanto pela perspectiva do desenvolvimento rural quanto do turismo, o modelo de desenvolvimento com parâmetros e objetivos sumamente econômicos tem gerado severos custos ambientais e socioculturais para muitos setores da sociedade e seus territórios. Os programas de desenvolvimento tiveram forte impacto em diversas relações sociais, expandindo o ideário do urbano como 'bom', local de referência para morar, em detrimento do rural, espaço atrasado e esvaziado, onde a produção de alimentos passa a ser sumamente mecanizada, os agricultores que persistem tornam-se anônimos, e seu modos de vida passam a ser vistos como sinônimo de atraso (GRAZIANO DA SILVA, 1997).

Há diversas discussões que deslocam a premência do consumo ou do consumismo na ação de viajar, e mesmo do turismo convencional. Se colocarmos o foco no turismo enquanto atividade de lazer, e o lazer "não como simples questão de amenização ou alegria para a vida, mas como questão

4 Ver dissertações do Mestrado Profissional em Preservação do Patrimônio Cultura (PEP/ IPHAN) de Helena Tavares Gonçalves (2014) disponível em http://portal.iphan.gov.br/pagina/detalhes/442 e de Thais Felipe Rosa, disponível em http://portal.iphan.gov.br/pagina/detalhes/1142. 
mesmo de sobrevivência humana, ou melhor, de sobrevivência do humano no homem ${ }^{5 \text { " }}$ (MARCELLINO, 2001:17), abrimos outra perspectiva de análise para a questão. Ao focarmos em iniciativas que buscam a população e comunidades locais enquanto narradores e protagonistas de suas atividades produtivas, podemos deslocar a ação utilitarista para o impulsionamento de ações emancipatórias, uma espécie de contraponto a um sistema insustentável em termos sociais, culturais e ambientais, tanto no âmbito do Desenvolvimento Rural quanto do Turismo.

\section{CONTRAPONTO: O ESPAÇO RURAL VALORIZADO}

Atualmente e de forma paralela, o espaço rural tem sido valorizado também para fins não agrícolas, "capitaneado por questões ecológicas, preservação da cultura (...), lazer, turismo ou para moradia", de acordo com Graziano da Silva \& Del Grossi (s/d: 166) ${ }^{6}$. Diversas ações vem buscando o rural como espaço de referência, ressignificando-o, impulsionando o surgimento de novos fenômenos sociais, muitos deles envolvendo encontros, haja vista a crescente busca de lazer e vivências em espaços rurais e a preocupação contemporânea sobre a qualidade e a origem dos alimentos (MENASCHE, 2003).

Para Goodman (2003), uma 'virada de qualidade' vem se desenhando. Conceitos como os de enraizamento, confiança e território são então a chave para entender essa 'virada' nas práticas alimentares, onde Redes Alternativas Agroalimentares (AFNs, na sigla em inglês) podem criar novos espaços econômicos: nesse sentido, um novo paradigma de desenvolvimento rural estaria vinculado à valorização de determinados territórios, culturas e formas de produção (CRUZ \& SCNEIDER, 2010). Assim, o rural, a agricultura e os agricultores passam a ser vistos e reconhecidos por sua contribuição à sociedade e por suas funções de gestão de recursos naturais, práticas sustentáveis e de cuidado com a paisagem local e regional, indicando que a agricultura cada vez mais vem sendo entendida como um bem público (CARNEIRO, 2003). Agricultores familiares e ecologistas, populações tradicionais, vem recebendo atenção e incentivos de políticas púbicas a partir da compreensão de que suas práticas e saberes podem ser promotores de estratégias de produção.

A multifuncionalidade na agricultura familiar ${ }^{7}$ se associa à valorização econômica do fazer agrícola, como a qualidade dos produtos e a diversificação das atividades no interior dos estabelecimentos agrícolas (CARNEIRO, 2003), em que pese a agricultura como atividade principal em torno da qual giram as estratégias de manutenção dos grupos familiares nas localidades. Se por um

\footnotetext{
5 Talvez uma melhor redação, ou uma redação no atual contexto, tivesse o cuidado de não 'masculinizar' o discurso; porém, a atenção aqui está na questão do lazer enquanto elemento de humanização.

6 Documento "O novo rural brasileiro" para Oficina de Atualização do IAPAR, disponível em www.iapar.br/arquivos/File/zip_pdf/novo_rural_br.pdf.

7 Engloba agricultores familiares descendentes de imigrantes, ecologistas, povos tradicionais, assentamentos de reforma agrária, assim como outras práticas e configurações, a partir da noção cunhada por Carneiro e Maluf (2003).
} 
lado é clara a dificuldade de se viver da agricultura, por outro, a valorização do rural leva à diversificar atividades gerando renda, para além da produção alimentar e do autoconsumo.

A modificação da função produtiva tradicional incorporando atividades não agrícolas e serviços, traz consigo o aumento dos encadeamentos da agricultura com outros setores e o aumento das ocupações não agrícolas dos habitantes rurais, incrementando os níveis de pluriatividade do setor (FERRER et al, 2014). Conforme Schneider (2003: 77), essa expressão é uma "[...] referência analítica à disseminação do fenômeno da diversificação das atividades e das fontes de renda das unidades familiares agrícolas". A pluriatividade norteia cada vez mais a agricultura familiar, estendendo a atividade rural para funções como a comercialização em cadeias curtas, seja em feiras ${ }^{8}$, através de cestas $^{9}$, mercados de comércio justo ${ }^{10}$, e o turismo, como forma de venda direta e agregação de valor.

Importante observar que ao trabalhar territorialmente as cadeias agroalimentares relocaliza-se o espaço da produção e transparecem novos paradigmas de desenvolvimento rural. As cadeias curtas e as AFNs tendem a proporcionar fácil rastreabilidade dos produtos, transparência nos processos de comercialização e a referência da origem dos alimentos, designando qualidades e características territoriais, conforme se pode observar:

\begin{tabular}{|c|c|c|c|}
\hline $\begin{array}{l}\text { Relações } \\
\text { espaciais }\end{array}$ & $\begin{array}{c}\text { Cadeias convencionais } \\
\text { Deslocalizacão }\end{array}$ & & $\begin{array}{c}\text { Redes alternativas } \\
\text { Relocalizacão }\end{array}$ \\
\hline $\begin{array}{l}\text { Relações: } \\
\text { produtores }\end{array}$ & $\begin{array}{l}\text { Produção intensiva fechada; } \\
\text { descensão dos preços agrícolas, } \\
\text { entrada de fornecedores em } \\
\text { processos coorporativos }\end{array}$ & \multirow{5}{*}{ 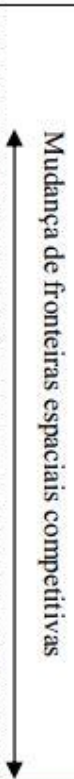 } & $\begin{array}{l}\text { Ênfase na qualidade; busca de } \\
\text { estratégias para agregar valor; novas } \\
\text { associações de produtores; } \\
\text { desenvolvimento novos nichos sócio } \\
\text { técnicos espacialmente localizados }\end{array}$ \\
\hline $\begin{array}{c}\text { Relações: } \\
\text { consumidores }\end{array}$ & $\begin{array}{l}\text { Ausência de referência espacial do } \\
\text { produto; não há encorajamento } \\
\text { para entender a origem do } \\
\text { alimento; produtos não } \\
\text { espacializados }\end{array}$ & & $\begin{array}{l}\text { Conhecimento variado do consumidor } \\
\text { sobre lugar, produção, produto e } \\
\text { condições espaciais de produção; } \\
\text { compra direta e também à distância }\end{array}$ \\
\hline $\begin{array}{l}\text { Processamento e } \\
\text { comercialização }\end{array}$ & $\begin{array}{l}\text { Sistemas de regulação rastreáveis, } \\
\text { porém privados e sem } \\
\text { transparência; padronização vs } \\
\text { produtos identificados } \\
\text { espacialmente }\end{array}$ & & $\begin{array}{l}\text { Saídas locais e regionais para } \\
\text { produção e comercialização; } \\
\text { fortemente variável, rastreável e } \\
\text { transparente; espacialmente } \\
\text { referenciado designando qualidades }\end{array}$ \\
\hline $\begin{array}{l}\text { Estruturas } \\
\text { institucionais }\end{array}$ & $\begin{array}{l}\text { Regulação pública e privada } \\
\text { fortemente burocratizada; } \\
\text { modelos de higienização que } \\
\text { reforçam a padronização }\end{array}$ & & $\begin{array}{l}\text { Desenvolvimento regional; } \\
\text { empoderamento na construção de } \\
\text { redes e infra-estrutura; suporte legal } \\
\text { local e regional }\end{array}$ \\
\hline $\begin{array}{l}\text { Estruturas } \\
\text { associativas }\end{array}$ & $\begin{array}{l}\text { Relações altamente tecnocráticas e } \\
\text { à distância; relações comerciais e } \\
\text { a - espaciais; falta de confiança e } \\
\text { conhecimento local }\end{array}$ & & $\begin{array}{l}\text { Relacionais, baseados em confiança, } \\
\text { local e regionalmente fundadas; redes } \\
\text { baseadas em linearidade; competitivo, } \\
\text { mas às vezes, colaborativo. }\end{array}$ \\
\hline
\end{tabular}

Fonte: Sonino \& Marsden, 2006. Tradução da autora, 2008.

8 Estudos de Wandsheer et al (2011) apontam as feiras como alternativa de grande potencial de retorno financeiro aos agricultores, que organizam o destino final dos produtos e estabelecem vínculos diretos com consumidores, ao mesmo tempo em que mantém suas atividades agropecuárias dentro de seus modos de vida e práticas usuais.

9 De acordo com os estudos de Preiss (2015), Preiss e Marques (2015).

10 Mercados rurais e urbanos que buscam diminuir a distância entre produtores e consumidores, agregando valor, remunerando melhor os produtores buscando informar a formação dos preços. Consultar Coelho de Souza, 2008, www.ifoam.org, www.fortalecer.com.ar. 
Como exemplo do diferencial que se cria a partir da conformação de Redes Alternativas, observa-se a criação de selos da Agricultura Familiar ${ }^{11}$ e certificações de alimentos de base ecológica ${ }^{12}$, que evidenciam a heterogeneidade sociocultural que the caracteriza, bem como o terroir $^{13}$ em relação aos vinhos, as identificações geográficas (IGs) e denominações de origem (DOs), que ao referenciarem o local de produção ou elaboração, permitem que os consumidores conheçam o vínculo entre as características de um produto e sua origem, o que propicia a agregação de valor aos produtos primários e/ou secundários e das cadeias envolvidas (CRUZ \& SCHNEIDER, 2010; BRASIL, 2008).

Também, referenciar e valorizar os patrimônios pode ser um meio para criar recursos específicos para um território com o intenso envolvimento dos atores locais (VEIGA, 2003). A partir do momento que a patrimonialização e valorização de produtos e processos tradicionais é uma ferramenta que possibilita a agregação de valor ${ }^{14}$, o turismo cria rotas e caminhos voltados à difusão desses produtos e dos saberes-fazeres, envolvendo diretamente os atores sociais portadores de conhecimentos específicos. Haja vista o Projeto Roteiros Nacionais de Imigração ${ }^{15}$, do Instituto do Patrimônio Histórico e Artístico Nacional - IPHAN, roteiros de enoturismo na serra catarinense ${ }^{16}$, os Caminos del Vino de Córdoba ${ }^{17}$, entre tantas outras rotas e pesquisas em curso ${ }^{18}$.

\section{O Local e o Comunitário no turismo e nas viagens}

O Turismo, e em especial o Turismo Rural, apresenta-se então pela perspectiva da valorização dos patrimônios, paisagens, modos de vida, saberes e práticas, podendo ser um fenômeno social humanizador (MOESCH, 2002; MARCELLINO, 2001), promotor de novas formas de cidadania que se dão através dos encontros. A atividade turística tende a induzir ao desenvolvimento sustentável quando planejada como meio integrador de diferentes interesses, a partir da complementariedade, agindo na preservação da memória do território que é a base do encontro entre visitantes e visitados.

11 Para verificar esse processo no Brasil, consultar www.mda.gov.br/sitemda/secretaria/saf-sipaf/sobre-o-programa e na Argentina, consultar http://servicios.infoleg.gob.ar/infolegInternet/anexos/245000-249999/249099/norma.htm.

12 Para mais informações acessar a tese de doutoramento de Maria Alice Mendonça "Sistemas Agroalimentares e Sustentabilidade: Sistemas de Certificação da Produção Orgânica no Sul do Brasil e na Holanda", 2015, disponível em www.lume.ufrgs.br/handle/10183/132925.

13 A expressão terroir referencia as raízes vinícolas de países europeus, buscando valorizar paisagens e fazeres locais para a promoção de seus vinhos. Na Argentina, Chile e outros países o uso da expressão é recente e traz o mesmo significado de forte ligação com o meio físico, associando questões agronômicas à belezas cênicas para de distinguir, valorizar e promover seus vinhos (Blume \& Specht, 2011).

14 A exemplo do Modo Artesanal de Fazer Queijo de Minas, inscrito no Livro de Registro dos Saberes (http://portal.iphan.gov.br/pagina/detalhes/65) e a inscrição do Ofício das Baianas de Acarajé no Livro dos Saberes do Patrimônio Cultural Imaterial do Brasil (http://portal.iphan.gov.br/pagina/detalhes/58).

15 Informações disponíveis em http://portal.iphan.gov.br/pagina/detalhes/671.

16 Ver www.turismo.sc.gov.br/atividade/enoturismo.

17 Ver www.cordobaturismo.gov.ar/audioguia/2636.

18 Como exemplo cito os estudos sobre o Queijo Serrano dos Campos de Cima da Serra de Fabiana Tomé da Cruz (ver produção textual em www.ufrgs.br/pgdr/publicacoes/producaotextual/fabiana-thome-da-cruz). 
Ao diversificarem seus repertórios de ação, os agricultores oferecem hospitalidade, comensalidade, informações e vivências como extensão de seu trabalho 'na roça'.

Ferrer et al (2013) conceituam da seguinte forma: no Agroturismo, a unidade de produção é quem organiza, gerencia e executa as atividades de acolhida, atrativos e consumo, e é na propriedade rural mesmo que se concentra a renda gerada; no Turismo em espaços rurais todo o planejamento para a organização e execução de atividades é realizado 'desde fora' do espaço rural, e em consequência, a maior parte da renda se concentra também fora do espaço rural; ao passo que no Turismo Rural todas as atividades de planejamento e de execução se localizam no espaço rural mais amplo que uma unidade produtiva, de forma que as rendas geradas são distribuídas na própria estrutura social mais ampla do empreendimento. Pela perspectiva e pela prática do INTA ${ }^{19}$ (Instituto Nacional de Tecnología Agropecuária - Argentina), que coloca o turismo rural sob uma perspectiva de desenvolvimento territorial, a ênfase da atividade se dá na revalorização da identidade territorial, aportando melhorias na qualidade de vida das populações rurais a partir do resgate de atividades econômicas tradicionais, melhorias em infraestrutura, cuidado e valorização do patrimônio cultural, diversificação e incremento de ingressos e reinversão desses ingressos no território, além da criação de fontes de trabalho e renda especialmente para mulheres e jovens rurais, contribuindo com a viabilidade de trabalho e com sua permanência no meio rural.

Como um desdobramento, estaria o Turismo Rural Comunitário, "al que podemos conceptualizar como una forma de gestión del turismo que aúna tres perspectivas fundamentales: i) una sensibilidad especial con el entorno natural y las particularidades culturales; ii) la búsqueda de la sostenibilidad integral (social y natural) y; iii) el control efectivo del negocio turístico por parte de la comunidad" (Ferrer et al, 2014:03).

O diferencial entre os conceitos/ modalidades reside então na abrangência dos atores sociais (individuais ou coletivos) envolvidos na atividade, bem como em sua 'atuação'. No Turismo em espaços rurais, se preproduzem as prátias do turismo convencional, pois se utiliza o espaço rural como ambiência e paisagem, porém sem envolver a comunidade local no protagonismo da atividade turística - quando muito, como prestadora de algum serviço ou empregando mão de obra local. Se no Agroturismo toda a atividade (produtiva e turística) é realizada dentro da propriedade rural, no Turismo Rural o circuito se expande para espaços e atividades da comunidade rural mais ampla, contemplando também atores sociais não-agricultores, residentes e pertencentes à comunidade rural, e no Turismo Rural Comunitário, os aspectos ambientais, ecossistêmicos e culturais, além da

19 Análise do crescimento das experiências de Turismo Rural apoiadas pelo INTA, entre 2004 e 2010, no marco do Programa Federal de Apoyo al Desarrollo Rural Sustentable (ProFeder) - Argentina, disponível em www.ucar.gob.ar/index.php/biblioteca-multimedia/evaluaciones/482-proyecto-nacional-de-turismo-rural-pronatur-magyp, acessado em agosto de 2016. 
gestão integral do turismo receptivo por parte da comunidade local são considerados. É o caso dos artesãos, de comércios locais articulados com a venda de produtos locais, a criação de de entrepostos de comercialização, de feiras locais, de atrativos públicos ou privados como campings, balneários, ou mesmo a prestadores de serviços como o de transporte (em diferentes meios, que pode ser de uma charrete a uma pick-up), por exemplo. É importante situar que em todas essas modalidades de turismo as atividades de prestação de serviços aos viajantes são complementares às atividades relacionadas à agricultura (ou ao extrativismo) no local de trabalho dos agricultores. Pela perspectiva do planejamento do turismo voltado para o benefício das comunidades rurais, é necessária a continuidade das atividades da propriedade rural, configurando o turismo como uma renda complementar, de forma a não converter os agricultores em prestadores de serviços dependentes unicamente da atividade turística.

No Turismo Rural e Comunitário a acolhida a visitantes toma uma abrangência ampla, conformando circuitos a partir da organização de serviços e produtos que se complementam, abrangendo diversos espaços em uma determinada comunidade - sejam propriedades, espaços de uso comunitário, espaços públicos e bens comuns. Dessa forma, coletivamente, a comunidade alcança ter um produto turístico, se desenham circuitos de lazer, de intercâmbio, de conhecimento, de vivências no rural, de consumo de alimentos em seu local de produção, processados e elaborados pelos guardiões de saberes tradicionais relacionados a esses produtos, e nesse sentido, são incentivados circuitos de promoção e de preservação dos diversos patrimônios das comunidades envolvidas.

Para os fins deste ensaio, localizo o Turismo Rural (TR) e Turismo Rural Comunitário (TRC) como modalidades que tendem a fomentar a produção e reprodução de cadeias agroalimentares vinculadas e geradas pela agricultura familiar e pela agroecologia. A relação que a organização para o turismo traz à tona para o debate do Desenvolvimento Rural é que a acolhida a visitantes, a organização de rotas e atrativos, na lógica do TRC tornam-se possibilidades para a gestão (comunitária, local) de (seus) recursos materiais e imateriais. O turismo, pela perspectiva da pluriatividade e da multifuncionalidade da agricultura (CARNEIRO \& MALUF, 2003) torna-se uma possibilidade de renda complementar, de preservação e uso de patrimônios, de reconhecimento e valorização de identidades, de reprodução ou de manutenção de modos de vida tradicionais (preservação e memória social), de cuidado e proteção de elementos naturais e ecossistemas. O turismo assim pensado engloba fortemente o aspecto da comercialização, e a partir desse viés inicialmente relacionado à 'geração de renda', podemos buscar identificar e reconhecer os processos 'subjetivos' vinculados: a valorização das identidades sociais e seus patrimônios, as formas de sociabilidade das famílias rurais e também, a busca por Segurança Alimentar e Nutricional. 
Cabe ressaltar que a segurança alimentar é um direito social dos povos, e nesse sentido, se dá também o direito e a necessidade de que os povos definam e controlem seus sistemas de alimentação e de produção de alimentos. Alimentos relacionados à soberania e segurança alimentar são aqueles que são suficientes, nutritivos, produzidos de forma ecológica e culturalmente apropriados. A produção proveniente da agricultura ecológica, tradicional, familiar, pela pesca e pastoreio tradicional representa esta produção 'segura' e suficiente. Como a comida produzida em um local pode contribuir com a manutenção do tecido social e cultural no meio rural (MALUF, 2003), sendo ao mesmo tempo, um elemento de 'apropriação comunitária' e um serviço prestado ou produto destinado aos visitantes? Em metáfora usada recentemente em uma situação de consultoria para o nascimento de um empreendimento rural de 'cama e café-da-manhã', no Rio Grande do Sul, "como oferecer um café da manhã em uma hospedaria rural pode ser uma ação coletiva no território"?

Ao agregar ao Turismo Rural a dimensão comunitária, o turismo configura-se para os agricultores e comunidade local como uma forma de ação coletiva, institucionalizada no território de uma comunidade, onde os atores sociais deixam de ser objetos passivos de um modelo ao se converterem em atores ativos do desenvolvimento, envolvendo-se em todas as etapas de implantação e execução da atividade turística receptiva, sendo os atores sociais da comunidade, organizados, quem exercem o controle efetivo do 'negócio turístico' (CAVACO, 2011).

O conceito de Turismo Rural Comunitário extrapola a noção instrumental de Turismo Rural, onde as atividades de planejamento e de execução de atrativos e serviços se localizam no espaço rural de forma que as rendas geradas são distribuídas na própria estrutura (FERRER et al, 2014). Aqui, então, se coloca a noção de agência proposta por Guiddens (1984), que demonstra que os atores sociais tem a habilidade de agir dentro de suas redes de relações, sendo assim sujeitos ativos, reflexivos, que exercem escolhas, articulam-se, movem-se na comunicação e nos espaços, e são capazes de agir e transformar sua própria realidade. A organização dos agricultores pode ser interpretada dentro do campo da ação coletiva, e portanto, ser definida como "el resultado de intenciones, recursos y límites, una orientación intencional construida mediante relaciones sociales desarrolladas en un sistema de oportunidades y obligaciones" (MELUCCI 1994, consultado em FERRER el al, 2014).

Estudos realizados pelo IICA Argentina ${ }^{20}$ (Instituto Interamericano de Cooperação para a Agricultura) apontam para a estreita relação da sustentabilidade do turismo rural com a promoção da segurança e soberania alimentares, onde o turismo deve integrar-se às estratégias de soberania alimentar e, inclusive, regular-se por essas estratégias. À noção de sustentabilidade, relaciono as 
características sociais, produtivas e nutricionais da agricultura familiar de base ecológica e da agroecologia por sua função de conservação da agrobiodiversidade e a produção de alimentos sãos ${ }^{21}$. A questão da sanidade dos alimentos refere-se aos estudos sobre contaminação de alimentos por uso de agrotóxicos, que relacionam então a agricultura ecológica com a saúde pública.

\section{Considerações e questões}

A mobilidade de fluxos, recursos e capitais, seja fisicamente através dos deslocamentos cada vez mais facilitados, seja simbólica e mesmo virtualmente, é uma característica contemporânea, e se apresenta como um aspecto interessante e pouco explorado nos estudos de desenvolvimento rural, talvez em função da novidade que é o tema dos serviços associados às cadeias curtas de alimentos de proximidade. De acordo com Lemos, Arroyo e Silveira "as novas feições da cidade e do campo nos chamam a uma permanente teorização e à interpretação dos diversos lugares. O movimento torna-se uma manifestação central do espaço geográfico e daí a necessidade de abordar práticas sociais como o turismo" (2006: 11).

A exemplo de experiências europeias de revitalização de territórios rurais, outros países vem incentivando o turismo a partir de organizações comunitárias. Chile, Argentina e Uruguai apresentam significativo aumento de ocupações geradas pela prestação de serviços turísticos no meio rural (BRASIL, 2008). No Brasil essa oferta é relativamente baixa. A característica do turismo rural brasileiro é de uma grande concentração de redes hoteleiras multinacionais e serviços oferecidos por empresas de grande porte (ROMÁN, 2009; BRASIL 2008), gerando consideráveis fluxos turísticos porém sem que os territórios e comunidades sejam beneficiados.

Brasil e Argentina são países vizinhos, onde a expansão e o avanço das fronteiras agrícolas possui importância estratégica para as políticas nacionais. Ambos os países compartilham diversas características socioculturais, principalmente em relação à região Sul do Brasil, especialmente no que se refere às políticas agrícolas. Também em ambos os países a perseverante insegurança alimentar contrasta com a grande importância (em quantidade e diversidade) da produção oriunda da agricultura familiar, que precisa encontrar formas diversas de comercialização ${ }^{22}$.

No marco dessas questões, se percebem campos de forças distintos tencionando e disputando modelos e projetos de desenvolvimento. Se coloca em questão a possibilidade de 'fomento' à Segurança Alimentar através do turismo em função de 1. Proporcionar fortes circuitos de cadeias curtas agroalimentares a partir do momento em que aproxima diretamente consumidores

21 Consultar Associação Brasileira de Saúde Pública (http://abrasco.org.br/dossieagrotoxicos) e Organização Mundial de Saúde (http://www.who.int/ipcs/assessment/public_health/pesticides/es).

22 Consta na Agenda 2030 para o Desenvolvimento Sustentável da ONU (2015) a necessidade de criação de cadeias de produção e abastecimento mais eficientes e sustentáveis (www.undp.org/content/undp/es/home/sdgoverview/post-2015development-agenda/goal-12.html). 
finais e produtores rurais; 2. Impulsiona a organização social de grupos familiares e de comunidades rurais para a realização do trabalho organizado para receber visitantes; 3 . Propicia a visibilidade e a ampla comunicação de 'pautas políticas' que estejam em questão por parte dos produtores rurais, através do contato direto com os visitantes, de organização de atrativos criados para o turismo e da ampla comunicação que a atividade turística demanda e 4 . Relocaliza o local de produção de alimentos a partir do contato dos visitantes com o ambiente rural, com "as práticas e representações particulares a respeito do espaço, do tempo, do trabalho, da família" (WANDERLEY, 2009:204) que remetem à construção social de uma ruralidade, relacionando modos de vida e identidades ao contato com a natureza, preservação de paisagens e valorização de patrimônios.

As práticas de Turismo Rural e Comunitário são relativamente novas. Emergem estudos e discussões que ajudam a compreender criticamente e a amadurecer as análises sobre o tema, em especial pela perspectiva do Desenvolvimento Rural. Tem se configurado como alternativa e contraponto ao sistema convencional de turismo, ou antes, de viagens organizadas, o que abarca fortes conexões entre o urbano e o rural, envolvendo a relação de consumidores-viajantes e agricultores-comensais, prestadores de serviços, e em grande medida, implicando mediadores sociais e serviços associados.

\section{REFERÊNCIAS}

BENI, M. Análise Estrutural do Turismo 1. ed. São Paulo: SENAC,1998.

BUADES, J. Exportando Paraisos: La colonización turística del planeta. Barcelona: Alba Sud Editorial, Colección Turismos: 2014.

BLUME, R.; SPECHT, S. Terroir, recursos e inovação à promoção do enoturismo. In Turismo Rural: Iniciativas e inovações. Souza, Marcelino de e Elesbão, Ivo (Orgs). Porto Alegre: Editora da UFRGS, 2011.

BRASIL. Ministério do Turismo. Turismo rural: orientações básicas. Ministério do Turismo, Secretaria Nacional de Políticas de Turismo, Departamento de Estruturação, Articulação e Ordenamento Turístico, Coordenação Geral de Segmentação. - Brasília: Ministério do Turismo, 2008. 53 p.

CARNEIRO, M. J. Agricultura, meio ambiente e turismo: desafios para uma agricultura multifuncional (Nova Friburgo, RJ). (88-103). In: Para além da Produção: Multifuncionalidade e Agricultura Familiar. Carneiro, Maria José e Maluf, Sérgio (Orgs.). Rio de Janeiro - MAUAD, 2003.

CARNEIRO, M. J. ; MALUF, S. (Orgs.) Para além da Produção: Multifuncionalidade e Agricultura Familiar. Rio de Janeiro - MAUAD, 2003 
CAVACO, C. Turismo Rural Comunitário (TRC) e desenvolvimento local na América Latina - Um olhar europeu. In Turismo Rural: Iniciativas e inovações. Souza, Marcelino de e Elesbão, Ivo (Orgs). Porto Alegre: Editora da UFRGS, 2011

COELHO DE SOUZA, J. Comércio solidário na prática do Núcleo Litoral Solidário da Rede Ecovida de Agroecologia. Programa de Pós-graduação em Desenvolvimento Rural, Departamento de Faculdade de Ciências Econômicas, Universidade Federal do Rio Grande do Sul, Porto Alegre, 2008.

CONTERATO, M. A.; FILLIPI, E. E. Teorias do Desenvolvimento. Planejamento e Gestão para o Desenvolvimento Rural da SEAD/UFRGS. Porto Alegre: Editora da UFRGS, 2009.

CRUZ, F. T.; SCHNEIDER, S. Qualidade dos Alimentos, escalas de produção e valorização de produtos tradicionais. Revista Brasileira de Agroecologia. 5(2): 22-38 (2010).

DAL SOGLIO, F.; OGLIARI, J.; MACHADO, A.; ALMEIDA, J.; SIMON DE BOEF, W. Metodologias participativas e a geração de biotecnologias apropriadas para o desenvolvimento rural sustentável. In: Biodiversidade e Agricultores: fortalecendo o manejo comunitário. Walter Simon de Boef (et al) editores. Porto Alegre, RS. Editora L\&PM, 2007.

FERRER, G.; BARRIENTOS, M.; SAAL, G. Intervención y organización campesina. El caso de Copacabana en la provincia de Córdoba (Argentina). Mundo Agrario, vol. 14, no 27, diciembre 2013.

FERRER, G.; BARRIENTOS, M.; SAAL, G.; MIR, A. El turismo rural como alternativa para el desarrollo en el norte de la provincia de Córdoba. Revista FAVE - Ciencias Agrarias 12 (1 - 2) 2014.

GIDDENS, A. The constitution of society: an outline of the theory of structuration. Cambridge, Polity Press, 1984.

GOODMAN, D. The quality 'turn' and alternative food practices: reflections and agenda. Journal of Rural Studies, v. 19, p.1-7, 2003.

GOODMAN, D.; REDCLIFFE, M. Environment and Development in Latin America: The Politics of Sustainability. Manchester: Manchester University Press, 1991.

GRAZIANO DA SILVA, J. O Novo Rural Brasileiro. Revista Nova Economia, Belo Horizonte. 7(1):43-81 (1997).

LEFF, E. Saber Ambiental. Petrópolis: Vozes, 2001.

LEMOS, A. I.; ARROYO, M.; SILVEIRA, M. L. América Latina: Cidade, campo e turismo. Conselho Latinoamericano de Ciencias Sociais, São Paulo, 2006.

MARCELLINO, N. C. Lazer e Humanização. Campinas, SP: Papirus, 2001

MELUCCI, A. Asumir un compromiso: identidad y movilización en los movimientos sociales. Zaragoza: Revista Zona Abierta (69). (1994) pp. 153-178, apud FERRER, G.; BARRIENTOS, M.; SAAL, G. Intervención y organización campesina. El caso de Copacabana en la provincia de Córdoba (Argentina). Mundo Agrario, vol. 14, no 27, diciembre 2013. 
MENASCHE, R. Os grãos da discórdia e o risco à mesa: um estudo antropológico das representações sociais sobre cultivos e alimentos transgênicos no Rio Grande do Sul. 2003. 287f. Tese (Doutorado em Antropologia Social) - Programa de Pós-Graduação em Antropologia Social. Instituto de Filosofia e Ciências Humanas. Universidade Federal do Rio Grande do Sul, Porto Alegre, 2003.

MOESCH, M. M. A produção do saber turístico. São Paulo: Contexto, 2002.

NOSCHANG, Juliane. O modelo teórico do SISTUR diante da complexidade do fenômeno turístico. Dissertação (mestrado), Universidade de Brasília, Centro de Exelência em Turismo. Brasília, 2014.

OTTMANN, G. et al (Orgs). Introducción a la agroecología de las emergencias. Córdoba: da Universidade de Córdoba, 2012. 41 p.

PACIFICO, D. História da modernização da agricultura: Um conto de muitas facetas In: Agricultura e sustentabilidade. DAL SOGLIO, F.; KUBO, R. R. (orgs.). Porto Alegre: Editora da UFRGS, 2009.

PLOEG, J. D. Sete teses sobre a agricultura camponesa. Revista Agriculturas: experiências em agroecologia, Rio de Janeiro, n., p.17-32, 2009.

PREISS, P. V. Contra-tendências agroalimentares: os saberes, o cuidado e a política no contexto de iniciativas colaborativas de compras. 2015. 143 f. Projeto de Qualificação de Tese (Doutorado em Desenvolvimento Rural) - Programa de Pós Graduação em Desenvolvimento Rural, Universidade Federal do Rio Grande do Sul. Porto Alegre, 2015

PREISS, P. V.; MARQUES, F. C. Tendências no movimento de re-localização alimentar brasileiro: uma análise de Iniciativas Colaborativas de Compras. Tessituras, Pelotas, v. 3, n. 2, p. 269-300, jul./dez. 2015.

RAYNAUT, C. Ideal e material, em busca de novos paradigmas: o papel da interdisciplinaridade. Conferência ministrada no Curso de Doutorado em meio ambiente e Desenvolvimento/UFPR, março 2006.

ROMÁN, M. F. Turismo Rural en Argentina: concepto, situación y perspectivas. Buenos Aires: IICA, 2009.

SCHNEIDER, S. (Org.). A pluriatividade na agricultura familiar. Porto Alegre: Editora da UFRGS, 2003.

SONNINO, R.; MARSDEN, T. Beyond the divide: rethinking relationships between alternative and conventional food networks in Europe. Journal of Economic Geography, v. 6, n. 2, p. 181-199, 2006.

VEIGA, J. E. Cidades imaginárias: $O$ Brasil é menos urbano do que se calcula. Campinas: Autores Associados, 2003.

WANDSHEER, E. A. R.; SOUZA, M.; LINDNER, M. Iniciativa de produtores rurais vinculada ao turismo rural de residência secundária: o caso da Feirita de Itaara/RS. In Turismo Rural: Iniciativas e inovações. Souza, Marcelino de e Elesbão, Ivo (Orgs). Porto Alegre: Editora da UFRGS, 2011.

WANDERLEY, M. N. B. O mundo rural como um espaço de vida: reflexões sobre a propriedade da terra, agricultura familiar e ruralidade. Porto Alegre: Editora da UFRGS, 2009. 